\title{
Size selection of Antarctic krill (Euphausia superba) in a commercial codend and trawl body
}

Herrmann, Bent; Krag, Ludvig Ahm; Krafft, Bjørn A.

Published in:

Fisheries Research

Link to article, DOI:

10.1016/j.fishres.2018.05.028

Publication date:

2018

Link back to DTU Orbit

Citation (APA):

Herrmann, B., Krag, L. A., \& Krafft, B. A. (2018). Size selection of Antarctic krill (Euphausia superba) in a commercial codend and trawl body. Fisheries Research, 207, 49-54.

https://doi.org/10.1016/j.fishres.2018.05.028

\section{General rights}

Copyright and moral rights for the publications made accessible in the public portal are retained by the authors and/or other copyright owners and it is a condition of accessing publications that users recognise and abide by the legal requirements associated with these rights.

- Users may download and print one copy of any publication from the public portal for the purpose of private study or research.

- You may not further distribute the material or use it for any profit-making activity or commercial gain

- You may freely distribute the URL identifying the publication in the public portal

If you believe that this document breaches copyright please contact us providing details, and we will remove access to the work immediately and investigate your claim. 
Research

Elsevier Editorial system(tm) for Fisheries

Manuscript Draft

Manuscript Number: FISH8081R1

Title: Size selection of Antarctic krill (Euphausia superba) in a commercial codend and trawl body

Article Type: Research Paper

Keywords: zooplankton fishery; size selectivity; sequential selectivity process

Corresponding Author: Dr. bent herrmann, Ph.D

Corresponding Author's Institution: SINTEF Fisheries and Aquaculture

First Author: bent herrmann, Ph.D

Order of Authors: bent herrmann, Ph.D; Ludvig A Krag, PhD; Bjørn A Krafft, PhD

Manuscript Region of Origin: DENMARK 


\section{Size selection of Antarctic krill (Euphausia superba) in a commercial codend and trawl 2 body}

3 Bent Herrmann ${ }^{1, a^{*}}$, Ludvig A. $\operatorname{Krag}^{2, a}$, Bjørn A. Krafft ${ }^{3, a}$

$4 \quad{ }^{1}$ SINTEF Fisheries and Aquaculture, Fishing Gear Technology, Hirtshals, Denmark

$5 \quad{ }^{2}$ DTU Aqua, Technical University of Denmark, Hirtshals, Denmark

$6 \quad{ }^{3}$ Institute of Marine Research, Bergen, Norway

$7 \quad{ }^{\mathrm{a}}$ These authors have equal authorship

$8 \quad *$ : Corresponding author. Tel.: +4598944300

$9 \quad$ E-mail address: Bent.Herrmann@ sintef.no (B. Herrmann).

Keywords: zooplankton fishery, size selectivity, sequential selectivity process

\section{Abstract}

During fishing, many fish species are able to avoid the net walls of the trawl body and so the majority of size selection occurs in the codend of the net. Antarctic krill (Euphausia superba) are regarded as true planktonic organisms passively drifting with currents, but they also display self-locomotion by active swimming. There is a lack of knowledge regarding the behavior of krill during the fishing process, and extrapolating results obtained for other species to krill is of limited value. In the case of krill, it is largely unknown to what extent the codend versus the trawl body contributes to the size selection process. The current study aims to quantify the size selection of krill in a commercially applied codend during experimental fishing. Combining these results with a model for full trawl size selectivity it was possible to provide an insight to the size selection process in the trawl body. Specifically, the study applied a two-step approach by first estimating the size selectivity of a commercial codend and second used the codend size selectivity obtained in this study to estimate the trawl body 
size selectivity of a commercial trawl based on entire trawl-selectivity obtained in a previous study. The results of this two-step analysis revealed that the trawl body contributes significantly to the total size selection process, demonstrating that size selectivity of Antarctic krill in commercial trawls is affected by both the trawl body and the codend.

\section{Introduction}

Several fish species avoid the netting of trawls during capture (Wardle, 1993) and so the majority of size selection for those species occurs in the codend of the trawl (Wileman et al., 1996). Other species, such as smaller invertebrates, may display a different pattern of behavior. For example, prawns tend to display a more limited response to trawl stimuli (Lochhead, 1961; Newland \& Chapman, 1989) and size selection resembles more of a sieving process in which individuals may meet the trawl netting frequently and with a more random orientation. Polet (2000) found that it was mainly the rounded lateral part of the net belly that was responsible for size selectivity for Crangon shrimps (Crangon crangon). Antarctic krill (Euphausia superba) are generally regarded as true planktonic organisms that drift with the currents, however they also display the ability to move horizontally and vertically in the water column, by swimming at higher speeds for limited periods of time (Marr, 1962; Kanda et al. 1982). Krag et al. (2014) speculated if size selection may occur throughout the entire trawl body when harvesting Antarctic krill.

Size selectivity results and underwater video recordings indicate that Antarctic krill escape through the mesh head first, at an angle perpendicular to the netting wall (Krag et al., 2014). This suggests that individual krill are either able to orientate themselves optimally in relation to the net mesh to facilitate their escape or, alternatively, their escape is a random process, where frequent contact with the trawl netting will result in some krill meeting the netting at an optimal orientation for escape by chance. Recent trawl designs in the fishing industry also 
support these mechanisms: Traditional net designs in the krill fishery comprised midwater trawls (Budzinski et al., 1985) with large openings (e.g. 60x50m) and large meshes near the mouth of the net with a successive reduction in size towards the small meshed codend. More recent designs comprise small mouthed (20x20m), low-tapered trawls with small meshes throughout the length of the trawl body (Bakketeig et. al, 2017). Detailed knowledge of the selection processes operating in fishing gear is important both in terms of understanding catch efficiency and gaining a better insight into ecosystem based management practices (Krafft et al., 2016).

Krag et al. (2014) assessed the selectivity of a full commercial trawl. However, it is unknown whether their results represented size selection over the full trawl body, with krill having multiple random contacts with the mesh in the trawl body, eventually resulting in escape, or they were due to the fact that krill are very effective at orientating themselves towards the meshes at an angle that facilitates escape in the codend. Therefore, it is unknown to what extent trawl body and codend each contribute to the size selection in the trawl. If the majority of size selection occurs in the codend, management of size selection in the krill fishery would only require changes in codend design. However, if the trawl body is important, adjusting the gear selectivity would require changes to other parts of the trawl . Therefore, it is important to quantify size selection in commercial codends and trawl bodies . The current study aimed to provide data to bridge this knowledge gap. Specifically, the main objectives were:

- To quantify size selection in a commercial krill trawl codend.

- To investigate to what extent size selection of krill in commercial trawls is attributed to the codend and the main trawl body. 


\section{Materials and Methods}

To obtain the objects described above, the study applied a two-step approach: i) estimating the size selectivity of a commercial codend (sections 2.1 and 2.2); and ii) used the codend size selectivity obtained in this study to estimate the trawl body size selectivity of a commercial trawl based on entire trawl-selectivity obtained in a previous study under the assumption that the codend selectivity in both studies is similar (sections 2.2 and 2.3).

\subsection{Sea trials and gear specifications}

To quantify the size selection process that occur in the codend, a survey trawl with a codend of commercial mesh size was used. The codend was surrounded by a small-meshed cover to collect codend escapees. The trawling was carried out off the coast of the South Orkney Islands $\left(60^{\circ} 35^{\prime} \mathrm{S}, 45^{\circ} 30^{\prime} \mathrm{W}\right)$ in January and February 2014 and 2015, using the Norwegian commercial ramp trawlers FV Saga Sea (96m, $6000 \mathrm{hp}$ ) in 2014, and the FV Juvel ( $99.5 \mathrm{~m}, 8158 \mathrm{hp}$ ) in 2015. A $30 \mathrm{~m}$ long small mesh survey trawl ('Macroplankton trawl') was used (see Krafft et al., 2010; 2016; Krafft \& Krag, 2015), with a $6 \times 6$ m mouth and $7 \mathrm{~mm}$ netting from the trawl mouth to the end of the last tapered section. The trawl body and cover were supported by an outer $200 \mathrm{~mm}$ protection net (single $3 \mathrm{~mm}$ PE twine). The codend was $5 \mathrm{~m}$ long (stretched) with four similar panels joined into four selvedges. Each codend panel was 270 meshes wide forward and 96 meshes wide at the codline following a 3N2B cutting rate. The codend was about 440 meshes in circumference where the codend was closed and made of $16 \mathrm{~mm}$ (nominal; $15.4 \mathrm{~mm}$ measured) diamond mesh PA netting. The actual mesh size was obtained by placing a small sample of the codend netting on a flatbed scanner with no tension in the netting together with a measuring unit to determine the precise mesh size. Individual meshes in the picture were analysed in FISHSELECT software tool (Herrmann et al., 2009) using the built-in image 
analysis function, and mesh size was assessed following the procedures described in

Sistiaga et al. (2011). Standard mesh measuring methods using the OMEGA measuring gauge (Fonteyne, 2005), which are applied for larger mesh sizes, could not be used in this study because the measuring jaws are too large for the small mesh sizes used in the krill fishery.

A $26.5 \mathrm{~m}$ long cover comprised of $7 \mathrm{~mm}$ mesh was mounted to the codend to collect escaping individuals. To prevent the cover net from masking the codend, two aluminium hoops ( $4 \mathrm{~m}$ diameter) were used (Fig 1). The cover had a zipper to facilitate easy access to the codend catch. The trawl was towed at speeds of approximately 2.5 knots as used in the commercial fishery.

When a trawl was landed on deck, a random subsample of krill from both the codend and the cover was taken. The length of the krill in the subsamples were measured from the anterior margin of the eye to the tip of the telson excluding the setae, following Marr (1962). The catch data was sorted into $1 \mathrm{~mm}$ wide length classes with count numbers quantifying the number of krill belonging to each length class from the codend and cover catch, respectively. The total catch and the subsample were weighed for both cover and codend in all hauls.

Fig. 1: Covered codend sampling system used to collect krill codend escapees and retainers.

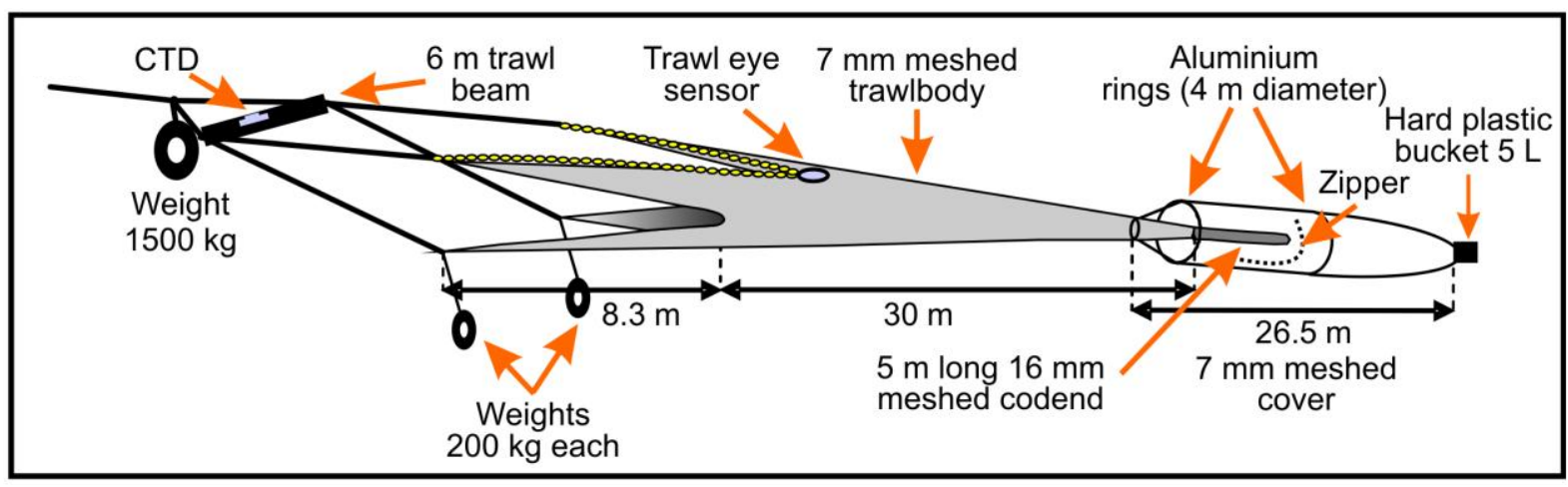


Data was pooled from different hauls in order to estimate average size selection over hauls $r_{a v}(l, v)$ (Herrmann et al., 2012), where $v$ is a vector consisting of the parameters of the size selectivity model and $l$ is the length of the krill. The purpose of this analysis is to estimate the values of the parameters $v$ that make the experimental data (averaged over hauls) most likely to be observed, assuming that the selectivity model is able to describe the data sufficiently well. Therefore, expression (1) was minimized with respect to parameters $\boldsymbol{v}$, which is equivalent to maximizing the likelihood for the observed data in form of the length-dependent number of krill retained in the codend $\left(n R_{j l}\right)$ versus those escaping to the cover $\left(n E_{j l}\right)$ :

$-\sum_{j=1}^{k} \sum_{l}\left\{\frac{n R_{j l}}{q R_{j}} \times \ln \left(r_{a v}(l, \boldsymbol{v})\right)+\frac{n E_{j l}}{q E_{j}} \times \ln \left(1.0-r_{a v}(l, \boldsymbol{v})\right)\right\}$

The outer summation in (1) is over $k$ hauls conducted and the inner summation is over length classes $l . q R_{j}$ and $q E_{j}$ are the sampling factors for the fraction of krill length measured in the codend and cover, respectively.

Four different models were chosen as basic candidates to describe $r_{a v}(l, v)$ : Logit, Probit, Gompertz and Richard (Wileman et al., 1996). The first three models are fully described by the two selection parameters L50 (length of krill with 50\% probability of being retained) and SR (difference in length between krill with $25 \%$ and $75 \%$ probability of being retained, respectively). The Richard model requires one additional parameter $(1 / \delta)$ that describes the asymmetry of the curve. The formulas for the four selection models, together with additional information, can be found in Wileman et al. (1996). In addition to the four classical size selection models (Logit, Probit, Gompertz, Richard), which assume that all individual krill entering the codend are subject to the same size selection process, we also considered one 
additional model that we refer to as the double logistic model DLogit (Herrmann et al., 2016).

The Dlogit model is constructed by assuming that a fraction $\mathrm{C}_{1}$ of krill entering the codend will be subject to one logistic size selection process with parameters $\mathrm{L}_{50}$ and $\mathrm{SR}_{1}$ while the remaining fraction $\left(1.0-\mathrm{C}_{1}\right)$ will be subject to an additional logistic size selection process but with parameters $\mathrm{L}_{5} 0_{2}$ and $\mathrm{SR}_{2}$. The rationale behind considering the DLogit model for the codend size selection of krill is the expectation that the selection process may constitute more than one process. Therefore, a total of five models were considered for $r_{a v}(l, v)$ :

$r_{a v}(l, v)=$

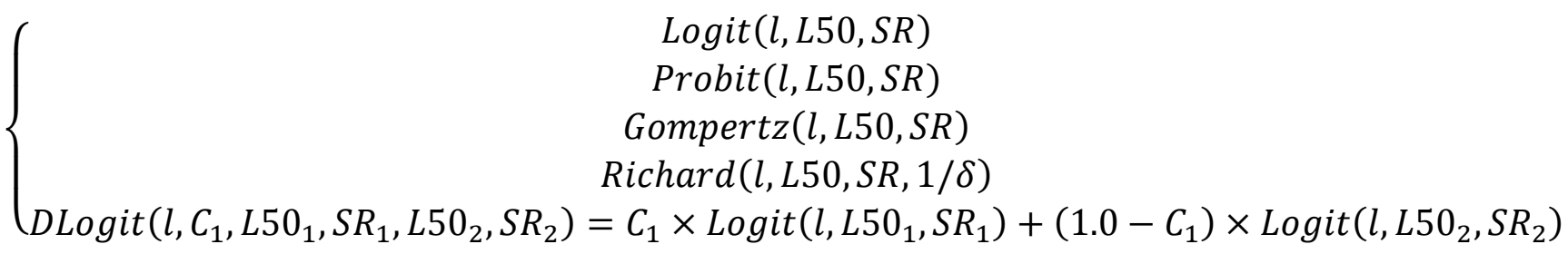
(2)

Each of the five models were fitted in (1). Selection of the best model of the five considered in (2) was carried out by comparing the AIC values for the model fit in (1). The selected model is the one with the lowest AIC value (Akaike, 1974). Evaluating the ability of a model to describe the data sufficiently is based on calculating the corresponding $p$-value, which expresses the likelihood of obtaining at least as big a discrepancy between the fitted model and the observed experimental data as would be expected by coincidence. Therefore, for the fitted model to be a candidate to model the size selection data, this $p$-value should not be below 0.05 (Wileman et al., 1996). In the case of a poor fit statistic ( $p$-value $<0.05$ ), the residuals were inspected to determine whether the result was due to structural problems when modeling the experimental data using the different selection curves or if it was due to overdispersion in the data (Wileman et al., 1996). 
Once the specific size selection model was identified, bootstrapping was applied to estimate the confidence limits for the average size selection. We applied the software tool SELNET (Herrmann et al., 2012) for size selection analysis and utilized the double bootstrap method implemented in this tool to obtain confidence limits for the size selection curve and the corresponding parameters. This bootstrapping approach is identical to the one described in Millar (1993) and takes both within-haul and between-haul variation into consideration. Each of the 1000 bootstrap repetitions conducted resulted in a "pooled" set of data which was analyzed using the identified selection model. The bootstrap results were used to estimate the Efron percentile $95 \%$ confidence limits for the selection curve and its parameters (Herrmann et al., 2012).

\subsection{Assessing contribution to full trawl size selectivity from trawl body}

The commercial trawl used by Krag et al. (2014) was a four panel Omega 7 krill trawl having a $400 \mathrm{~m}^{2}$ mouth opening $(20 * 20 \mathrm{~m})$ and a total length of about $220 \mathrm{~m}$. The trawl was supported by an outer netting ranging from $400 \mathrm{~mm}$ in $2 * 6 \mathrm{~mm}$ PE in the mouth area to $144 \mathrm{~mm}$ in $2 * 4 \mathrm{~mm}$ PE in the codend. $20 \mathrm{~N}$-cut in-liner sections in $16 \mathrm{~mm}$ PA netting were sequentially attached from the mouth of the trawl to the codend. These in-liners were only attached in the forward end and there was about $1 \mathrm{~m}$ overlap between in-liner sections. The codend was about 50m long having about 2000 meshes in circumference. The entire codend section was supported by an arrangement of roundstraps and lastridge ropes to provide strength to the section. The codend used during the experimental fishing in this study was made of the exact same netting as used in both the codend and the trawl body in the trials reported in Krag et al. (2014). This means that the two diamond mesh codends are identical with respect to at least two of the most important factors, mesh size and twine properties, for determining codend size selectivity (O'Neill \& Herrmann, 2007). For fish trawls number of meshes in codend circumference have been found to influence size selection 


$$
\begin{gathered}
r_{\text {total }}(l)=r_{\text {body }}(l) \times r_{\text {codend }}(l) \\
\Downarrow \\
r_{\text {body }}(l)=\frac{r_{\text {total }}(l)}{r_{\text {codend }}(l)}
\end{gathered}
$$

203 Where $r_{\text {body }}(l)$ is the size selectivity in the main trawl body and $r_{\text {total }}(l)$ is the full trawl size 204

in diamond mesh codends by affecting the openness of the meshes (Herrmann et al., 2007;

O'Neill and Herrmann, 2007; O'Neill et al., 2008; Wienbeck et al., 2011; Tokaç et al., 2016). However, for the small mesh krill codends we expect that the water flow acting on the netting will keep the meshes open and therefore lowering the potential influence of number of meshes in circumference on the codend size selection of krill. Therefore, despite not all codend design factor are identical, including number of meshes incercumference, we assume for explorative purposes that the two codends would have approximately similar size selectivity. Considering that the codend was attached to a small meshed survey trawl in the current study and to a commercial trawl in the study by Krag et al. (2014) we could interpret the difference in size selection between the experiments to be mainly due to size selection in the commercial trawl body as opposed to the codend. Therefore, any significantly higher retention probabilities for the size selection curve in the current study in comparison to the full trawl and codend size selectivity curve of Krag et al. (2014) are assumed to be caused by size selection in the commercial trawl body in Krag et al. (2014).

If we look at the size selection of the whole net from Krag et al. (2014) $r_{\text {total }}(l)$ as a sequential process we get: selectivity from Krag et al. (2014).

By using (2) and $r_{\text {total }}(l)$ from Krag et al. (2014) and the estimate for $r_{\text {codend }}(l)$ from the dataset in this study, an estimate for $r_{b o d y}(l)$ for the commercial trawl applied by Krag et al. (2014) was obtained. 95\% confidence intervals for $r_{b o d y}(l)$ are based on the two bootstrap 
populations of results (1000 bootstrap repetitions in each) from $r_{\text {codend }}(l)$ in the current study and $r_{\text {total }}(l)$ from Krag et al. (2014), respectively. As these values were obtained independently, a new bootstrap population of results for $r_{b o d y}(l)$ was created using:

$r_{\text {body }}(l)_{i}=\frac{r_{\text {total }}(l)_{i}}{r_{\text {codend }}(l)_{i}} \quad i \in[1 \ldots 1000]$

222

$$
\begin{aligned}
e_{\text {codend }}(l) & =\frac{1.0-r_{\text {codend }}(l)}{1.0-r_{\text {total }}(l)} \\
e_{\text {body }}(l) & =\frac{1.0-r_{\text {body }}(l)}{1.0-r_{\text {total }}(l)}
\end{aligned}
$$

In (4) the estimated $r_{\text {codend }}(l)$ and $r_{\text {body }}(l)$ as described in the previous two sections are used, in addition to $r_{\text {total }}(l)$ from Krag et al. (2014). Efron percentile 95\% confidence

225 intervals for $e_{\text {codend }}(l)$ and $e_{\text {body }}(l)$ were obtained by creating a new bootstrap file following the approach described for $r_{b o d y}(l)$ in the last section. 
A total of eight valid hauls were carried out during the sea trials in 2014/2015. Table 1

summarizes the catch data from these hauls. Fishing was based on acoustic registrations of

krill swarms resulting in relatively short towing times ranging from 13 to 57 minutes

(Table 1).

Table 1: Catch data and haul information. Haul 1 and 2 are from the 2014 cruise while the

remaining hauls are from the 2015 cruise.*: from time the gear is at fishing depth until it is on deck again.

\begin{tabular}{|c|c|c|c|c|c|c|c|c|}
\hline $\begin{array}{l}\text { Haul ID } \\
\text { (j) }\end{array}$ & $\begin{array}{l}\text { Number of } \\
\text { length } \\
\text { measurements } \\
\text { from codend } \\
\left(n R_{j}\right)\end{array}$ & $\begin{array}{l}\text { Number of } \\
\text { length } \\
\text { measurements } \\
\text { from cover }\left(n E_{j}\right)\end{array}$ & $\begin{array}{l}\text { Sampling } \\
\text { factor for } \\
\text { codend }\left(q R_{j}\right)\end{array}$ & $\begin{array}{l}\text { Sampling } \\
\text { factor for } \\
\text { cover }\left(q E_{j}\right)\end{array}$ & $\begin{array}{l}\text { Catch in } \\
\text { codend } \\
(\mathrm{kg})\end{array}$ & $\begin{array}{l}\text { Catch in } \\
\text { cover } \\
(\mathrm{kg})\end{array}$ & $\begin{array}{l}\text { Towing } \\
\text { duration } \\
(\min )^{*}\end{array}$ & $\begin{array}{l}\text { Maximum } \\
\text { towing } \\
\text { depth }(\mathrm{m})\end{array}$ \\
\hline 1 & 332 & 292 & 0.0015 & 0.0050 & 108 & 22 & 13 & 60 \\
\hline 2 & 481 & 270 & 0.0053 & 0.0450 & 61 & 3.5 & 19 & 111 \\
\hline 3 & 246 & 88 & 0.0137 & 0.0534 & 10 & 0.5 & 34 & 155 \\
\hline 4 & 237 & 40 & 0.1155 & 0.2780 & 1 & 0.05 & 47 & 160 \\
\hline 5 & 225 & 345 & 0.0016 & 0.0198 & 58 & 6 & 43 & 123 \\
\hline 6 & 249 & 345 & 0.0019 & 0.0222 & 50 & 7 & 27 & 155 \\
\hline 7 & 326 & 322 & 0.0180 & 0.2050 & 9 & 0.5 & 33 & 98 \\
\hline 8 & 414 & 442 & 0.0018 & 0.0086 & 15 & 0.25 & 57 & 106 \\
\hline
\end{tabular}

237

Length measurements were obtained for a total of 4654 krill during the cruises and these data form the basis for the analysis of codend size selection.

242 Each of the five size selection models considered (section 2.2) were fitted to the pooled size

243 selection data. Table 2 shows the AIC values for the fit of each model to the experimental

244 data and it is clear that average size selectivity was best described by the DLogit model.

245 Therefore the Dlogit model is selected to represent the codend size selection (Fig. 2) it is 
Table 2: AIC values for models. The model with lowest AIC value is highlighted in bold.

\begin{tabular}{ll}
\hline Model & AIC value \\
\hline Logit & 807872.17 \\
Probit & 808023.37 \\
Gompertz & 807795.25 \\
Richard & 807797.31 \\
DLogit & $\mathbf{8 0 7 0 5 0 . 6 6}$ \\
\hline
\end{tabular}

Fig. 2: On the top plot fit of the DLogit size selection model (black curve) to the

experimental retention rates (white diamond marks). The grey curve represents the raised experimental data.

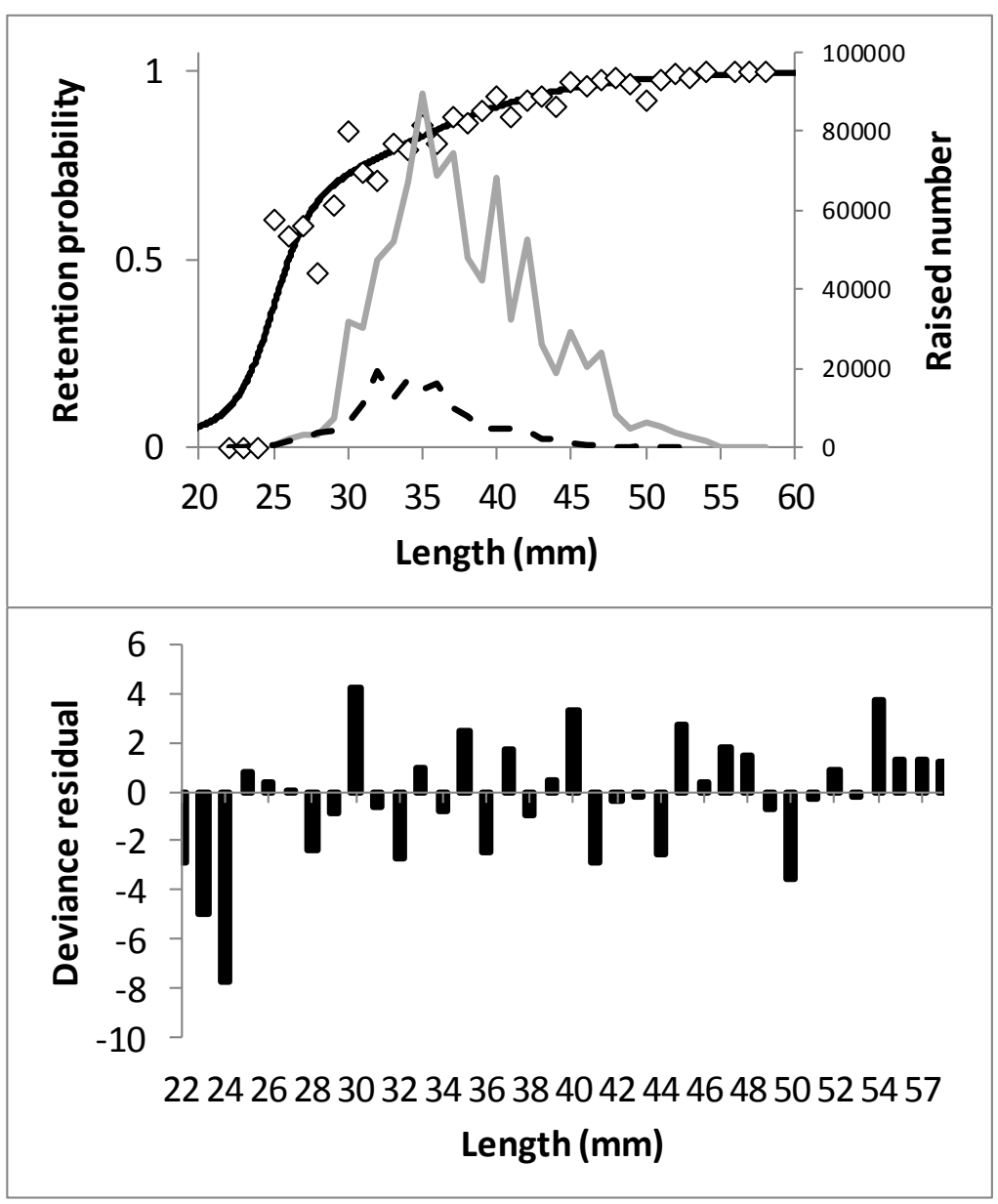


The fact that the DLogit model provided the best fit could indicate that size selection in a diamond mesh codend involves more than one size selection process, which is potentially caused by krill having few contacts with the mesh that facilitate escape in the codend (Frandsen et al., 2010; Herrmann et al., 2016). The two sets of selection parameters $\left(L 5 O_{l}\right.$, $\left.S R_{1}\right)$ and $\left(\mathrm{LSO}_{2}, \mathrm{SR}_{2}\right)$ can be interpreted as the selection parameters to represent the two different selection processes accounted for by the DLogit model (Table 3). The difference in values for $L 5 O_{1}$ and $L 5 O_{2}$ estimated at respectively $32.55 \mathrm{~mm}$ and $25.02 \mathrm{~mm}$ indicate a considerable difference in those two selection processes. The $p$-value $<0.05$ could indicate problems describing the experimental data, but as the deviation between experimental rates and the fitted curve as the deviance residual plot (Fig. 2) did not show any systematic patterns as only few consecutive residual values was found to have same sign. Therefore, it was assumed that the low p-value was caused by overdispersion in the data probably resulting from working with subsampled and data pooled over hauls. Based on this, it was assumed that the DLogit model can be applied to describe the size selection of krill in the codend.

Table 3: Selection parameters and corresponding fit statistics for DLogit modelling of codend selectivity data. Values in () represent $95 \%$ confidence limits.

\begin{tabular}{ll}
\hline $\mathrm{L} 50(\mathrm{~mm})$ & $26.04(13.82-29.19)$ \\
$\mathrm{SR}(\mathrm{mm})$ & $7.07(1.65-27.19)$ \\
$\mathrm{C}_{1}$ & $0.4361(0.0346-0.6889)$ \\
$\mathrm{L}_{5} 0_{1}(\mathrm{~mm})$ & $32.55(28.17-50.00)$ \\
$\mathrm{SR}_{1}(\mathrm{~mm})$ & $12.73(1.00-50.00)$ \\
$\mathrm{L}_{0} 0_{2}(\mathrm{~mm})$ & $25.02(16.87-33.18)$ \\
$\mathrm{SR}_{2}(\mathrm{~mm})$ & $2.69(1.00-26.35)$ \\
Deviance & 213.75 \\
DOF & 31 \\
$\mathrm{P}$-value & $<0.0001$ \\
\hline
\end{tabular}

3.2 Comparison with full trawl selectivity from former study and predicting trawl body size selection for trawl in the former study

The estimated codend size selectivity curve was compared with the full trawl selectivity curve obtained by Krag et al. (2014) (Fig. 3). 
278 Fig. 3: Size selectivity for: full trawl, codend and trawl body. Top: Comparison of size

279 selectivity curves for the codend in the current study (black curve) and for the full trawl by

280 Krag et al. (2014) (grey curve). Bottom: Predicted size selection curve for the trawl body in

281 the commercial trawl applied by Krag et al. (2014). Broken curves represent 95\% confidence

282 bands.

\section{Codend and full trawl size selectivity}

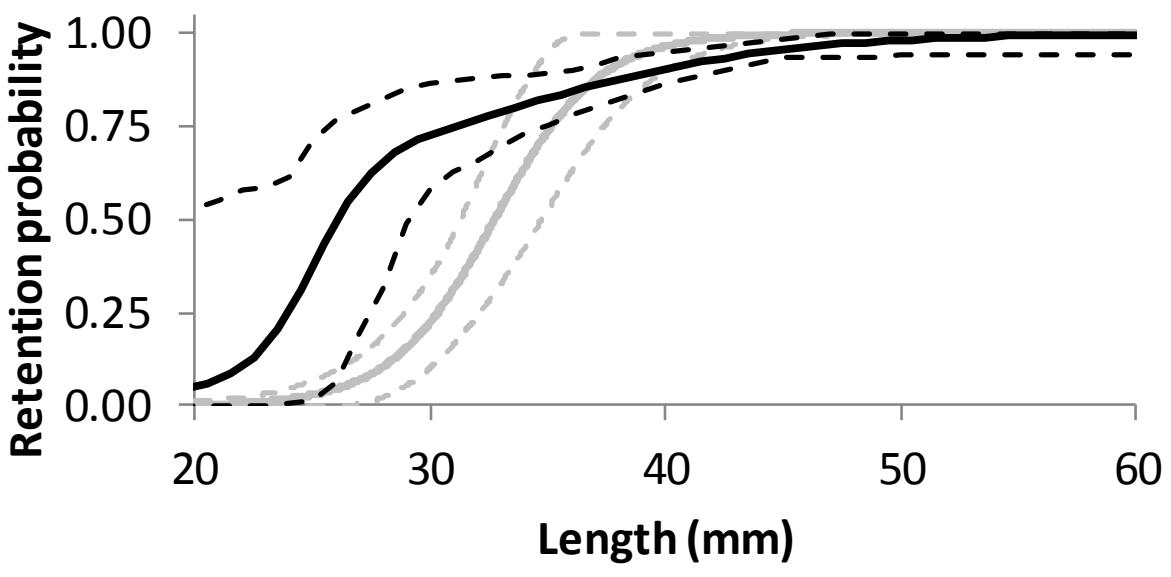

\section{Trawl body size selectivity}

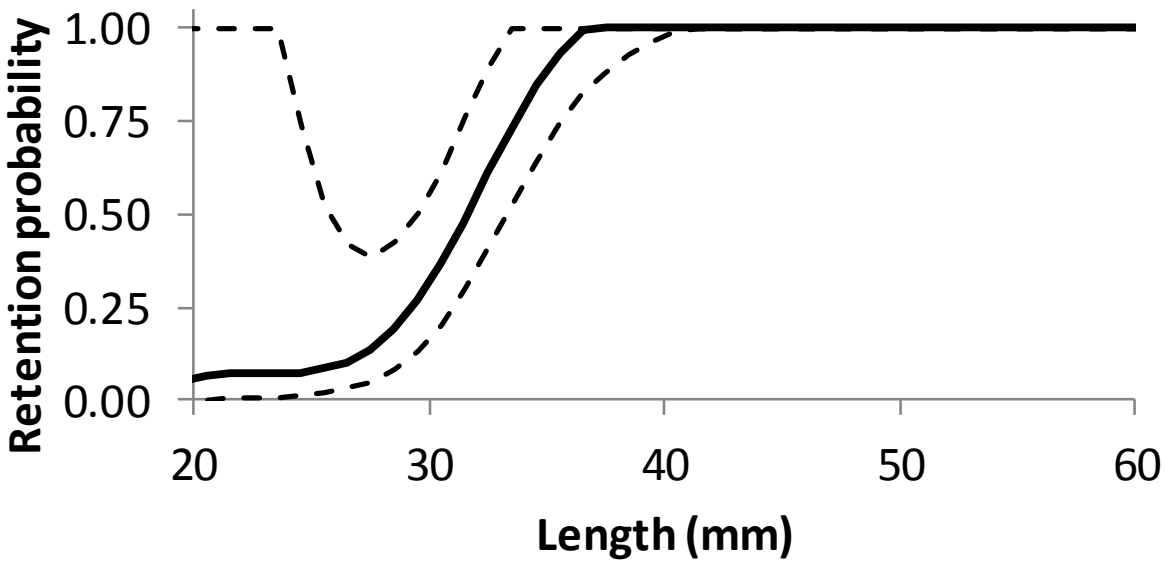

From Fig. 3 it is clear that the codend retains significantly higher proportions of krill between 
size selection was similar in both studies, it is likely that this difference is caused by size selection processes in the trawl body in the commercial trawl applied by Krag et al. (2014). For larger krill $(37-50 \mathrm{~mm})$ the codend size selection curve is estimated to have a slightly lower retention rate than the full trawl, which violates the assumption that the two codends have similar size selection. However, the confidence intervals of the two curves clearly overlap for krill of these sizes and therefore this result is not a violation of the assumption regarding similar codend size selection. Based on the size selection curves for the codend and the full trawl (Fig. 3, top), size selection in the trawl body for the commercial trawl applied by Krag et al. (2014) was predicted based on the method described in section 2.3 (Fig. 3, bottom).

From Fig. 3 it was predicted that the trawl body enables release of krill up to about $37 \mathrm{~mm}$ in length because the size selection curve first reach full retention above that size. Considering the confidence bands, significant size selectivity for krill ranging from $23-33 \mathrm{~mm}$ is predicted. The predicted trawl body release efficiency is high for krill up to $30 \mathrm{~mm}$ in length with less than $25 \%$ retained, demonstrating a considerable size selection process in the trawl body of the commercial trawl. For krill approximately $28 \mathrm{~mm}$ long, the upper confidence limit for the size selection curve is below $50 \%$, demonstrating that more than $50 \%$ of krill at that size entering the trawl will be released through the trawl body. The contributions of both the trawl body and the codend in size selection for the commercial trawl can be further illustrated by quantifying the length dependent fraction of the full trawl escape that can be obtained by the trawl body and codend provided from a standalone deployment. This is obtained by the method described in section 2.4, with results shown in Fig. 5. 
Fig. 5: Fraction of full trawl krill escape rate obtainable for the trawl body alone (top) and codend (bottom). Broken curves represent $95 \%$ confidence bands.

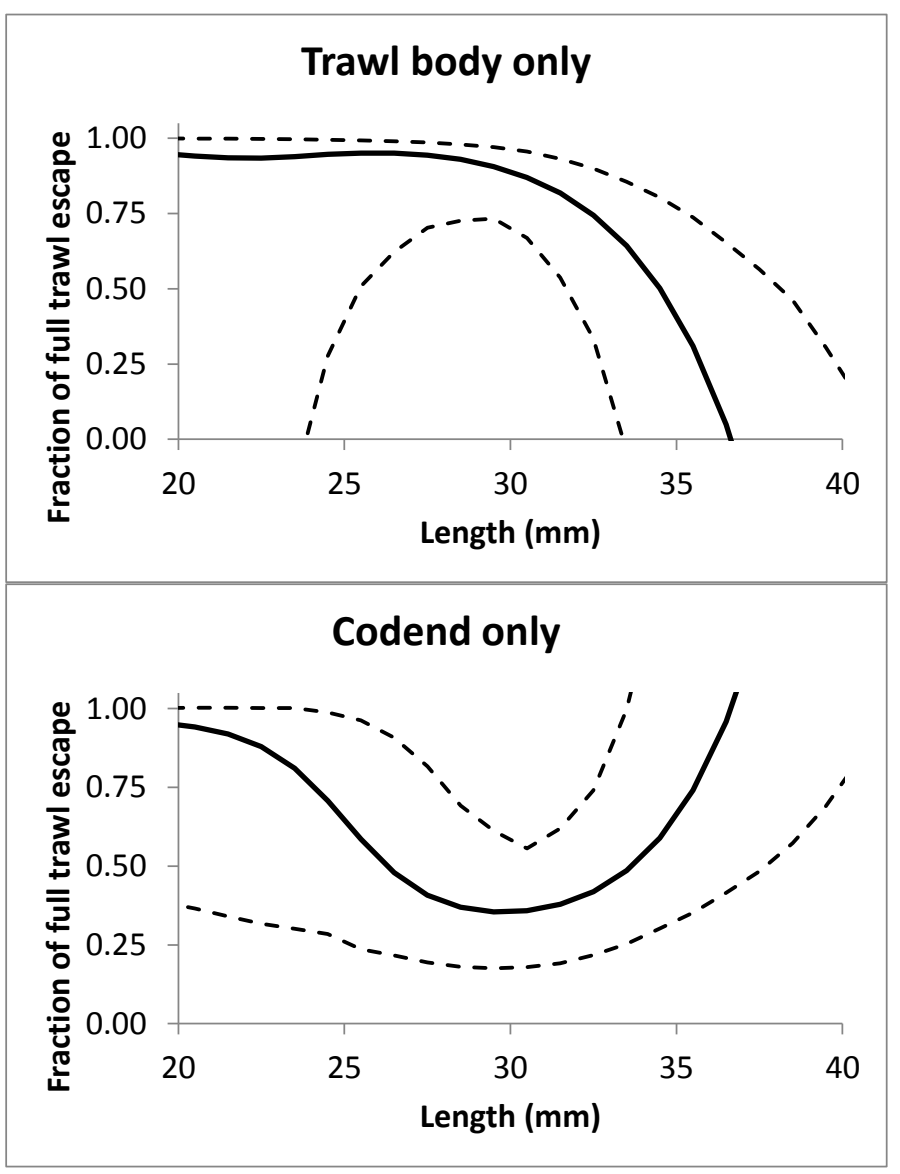

From Fig. 5 it is predicted that more than $80 \%$ of the full trawl escape rate can be obtained in the trawl body for krill up to $30 \mathrm{~mm}$ in length. For some sizes of krill, the fraction is very high with the lower significance limit above the $50 \%$ fraction (value above 0.5 ). In contrast, for the codend the upper limit for the release fraction does not exceed $75 \%$ for sizes of krill between 27 and $33 \mathrm{~mm}$ in length. The results in Fig. 5 clearly depict the potential contribution of both

322 the trawl body and the codend in total krill release through the meshes of the commercial trawl. 


\section{Discussion}

326 Detailed quantification of the size selection of both the codend and the trawl body is essential

327

328 to estimate escape mortality, and total removal by the fishery, for the optimization of gear design and the technical regulation of a fishery. In this study, the covered codend method was used to investigate size selectivity for Antarctic krill using a $16 \mathrm{~mm}$ diamond mesh codend. Codend selectivity was best described by the double logistic model, indicating that more than one process affects codend size selectivity. It is possible that only a small fraction of krill meet the codend mesh at an optimal orientation for escape and so a double logistic model is necessary to describe size selection in the codend, as opposed to a single logistic for the full trawl, as in Krag et al. (2014).

By combining new codend size selection results obtained within this study with results for full trawl size selectivity obtained in a former study, this study provided an insight into the size selection process in the main trawl body of the commercial trawl, contributing to an understanding of full trawl size selectivity.

This analysis demonstrates that the trawl body contributes significantly to the size selection process and that size selectivity of Antarctic krill is affected by the trawl body of commercial trawls and by the attached codend. Conclusions from this study are based on the assumption that the codend in the current study provides similar size selectivity for krill as the one used in the trials described by Krag et al. (2014). The same type of netting was used for both experiments, but it is possible that different fishing conditions could affect the predicted size selectivity. However, we expect the potential maximum difference in codend size selection is well within the confidence bands obtained in this study and thus is reflected in the uncertainties for the trawl body size selectivity. 
The results for trawl body size selectivity demonstrate considerable size selection for krill $<32$ $\mathrm{mm}$ using commercial $16 \mathrm{~mm}$ mesh. Therefore, this study has shown that commercial trawl bodies in krill-fishery can generally contribute to size selectivity. Nevertheless, a number of parameters (e.g. tapering of body) will influence the specific selectivity. Therefore, the specific findings about size selectivity of trawl body are not general, but an example for this specific gear used in Krag et al. (2014). Other trawl designs might have different selectivity. In this respect, it is important to mention that some commercial krill trawl designs include "flapper-panels", which prevent "stickers" and increase net avoidance (active or passive), enhancing transportation towards the codend (Bakketeig et. al, 2017). With such flappers mounted, the size selectivity in the trawl body could potentially be considerably lower than that estimated in Krag et al. (2104).

The current study found that for krill, size selectivity occurs across the entire trawl. This is different to what is observed for most fish species, but it is in keeping with results from fisheries targeting smaller crustaceans (e.g. Polet, 2000). The results of the current study revealed that a substantial fraction of size selectivity for Antarctic krill occurred in the trawl body ahead of codend. Such findings can be incorporated into fisheries management, where technical regulations should consider the entire trawl and not just the codend section.

\section{Acknowledgements}

The Institute of Marine Research in Norway and The Norwegian Research Council provided financial support (grant number 243619) for this study. We thank the two Norwegian fishing companies Rimfrost AS and Aker Biomarine AS, for providing their vessels and crew for the collection of data and thus making this field experiment possible. Finally, we want to express our gratitude to the anonymous reviewers for their valuable comments during the review process which helped improving this manuscript greatly. 


\section{References}

374 Akaike, H., 1974. A new look at the statistical model identification. IEEE Trans. Autom.

375 Control 19, 716-723.

376 Bakketeig, I.E., Hauge M., Kvamme, C. (Editors), 2017. Havforskningsrapporten 2017.

377 Fisken og havet, særnr. 1-2017 (in Norwegian). ISBN: 08020620.

378 Budzinski, E., Bykowski, P., Dutkiewics, D., 1985. Possibilities of processing and marketing

379 of products made from Antarctic krill. FAO Fisheries Technical Paper No. 268. Rome: FAO. $38046 \mathrm{p}$.

381 Frandsen, R., Herrmann, B., Madsen, N., 2010. A simulation-based attempt to quantify the 382 morphological component of size selectivity of Nephrops norvegicus in trawl codends. Fish. 383 Res. 101, 156-167.

384 Herrmann, B., Priour, D., Krag, L.A., 2007. Simulation-based study of the combined effect on 385 codend size selection for round fish of turning mesh 90 degree and of reducing the number of 386 meshes in the circumference. Fish. Res. 84, 222-232.

387 Herrmann, B., Krag, L.A., Frandsen, R.P., Madsen, N., Lundgren, B., Staehr, K.J., 2009.

388 Prediction of selectivity from morphological conditions: methodology and a case study on cod 389 (Gadus morhua). Fish. Res. 97, 59-71.

390 Herrmann, B., Sistiaga, M., Nielsen, K.N., Larsen, R.B., 2012. Understanding the size 391 selectivity of redfish (Sebastes spp.) in North Atlantic trawl codends. J. Northw. Atl. Fish. 392 Sci., 44, 1-13. 
Herrmann, B., Krag, L.A., Feekings, J., Noack, T., 2016. Understanding and predicting size selection in diamond mesh codends for Danish seining: a study based on sea trials and computer simulations. Marine and Coastal Fisheries 8, 277-291.

Kanda, K., Takagi, K., Seki, Y. 1982. Movement of larger swarms of Antarctic krill Euphausia superba off Enderby Land during 1976-1977 season. J Tokyo Univ Fish 68:2442.

Krafft, B.A., Krag, L.A., Engås, A., Nordrum, S., Bruheim, I., Herrmann, B., 2016. Quantifying the escape mortality of trawl caught Antarctic krill (Euphausia superba). PlosONE 11(9):e0162311 doi:10.1371/journal.pone.0162311.

Krafft, B.A., Krag, L.A., 2015. Assessment of mortality of Antarctic krill (Euphausia superba) escaping from a trawl. Fisheries Research 170:102-105.

Krafft, B.A., Melle, W., Knutsen, T., Bagøien, E., Broms, C., Ellertsen, B., Siegel, V., 2010. Distribution and demography of Antarctic krill in the Southeast Atlantic sector of the Southern Ocean during the austral summer 2008. Polar Biology 33:957-968

Krag, L.A., Herrmann, B., Iversen, S., Engås, A., Nordrum, S., Krafft, B.A., 2014. Size selection of Antarctic krill (Euphausia superba) in trawls. PloS ONE 9(8): e102168. doi:10.1371/journal.pone.0102168.

Lochhead, J.H., 1961. Locomotion. In: Waterman T.H. (Ed), The physiology of the Crustacea. Academic Press, New York, pp 313-356.

Marr, J. 1962. The natural history and geography of the Antarctic krill Euphausia superba. Discov Rep 32:33-46 
Millar, R. B. 1993. Incorporation of between-haul variation using bootstrapping and nonparametric estimation of selection curves. Fisheries Bulletin 91, 564-572.

Moore, D.S, McCabe, G.P., Duckworth, W.M., Sclove, S.L, 2003. Practice of Business

Statistics using data for decisions. Published by W. H. Freeman. ISBN 10: 0716757230 / ISBN 13: 9780716757238.

Newland, P.L., Chapman, C.J., 1989. The swimming and orientation behaviour of the Norway lobster, Nephrops norvegicus (L), in relation to trawling. Fisheries Research 8, 63-80.

O’Neill, F.G., Herrmann, B., 2007. PRESEMO- a predictive model of codend selectivity- a tool for fisheries managers. ICES Journal of Marine Science 64, 1558-1568.

O’Neill, F.G., Graham, N., Kynoch, R.J., Ferro, R.S.T., Kunzlik, P.A., Fryer, R.J., 2008.The effect of varying cod-end circumference, inserting a 'flexi-grid' or inserting a Bacoma type panel on the selectivity of North Sea haddock and saithe. Fish.Res. 94, 175-183

Polet, H., 2000. Codend and whole trawl selectivity of a shrimp beam trawl used in the North Sea. Fisheries Research, 48, 167-183.

Sistiaga, M., Herrmann, B., Nielsen, K.N., Larsen, R.B., 2011. Understanding limits to cod and haddock separation using size selectivity in a multi-species trawl fishery: an application of FISHSELECT. Can. J. Fish. Aquat. Sci. 68, 927-940.

Tokaç, A., Herrmann, B., Gökçe, G., Krag, L. A., Nezhade, D. S., Lök, A., Kaykaç, H., Aydın, C., Ulaş, A., 2016. Understanding the size selectivity of red mullet (Mullus barbatus) in Mediterranean trawl codends: A study based on fish morphology. Fish. Res. 174, 81-93.

Wardle, C.S., 1993. Fish behaviour and fishing gear. In: Behaviour of teleost fishes, 2nd edition. Pitcher TJ (Ed). Chapman and Hall, London. pp 609-644. 
436 Wienbeck, H., Herrmann, B., Moderhak, W., Stepputtis, D, 2011. Effect of netting direction

437 and number of meshes around on size selection in the codend for Baltic cod (Gadus morhua).

$438 \quad$ Fisheries Research 109: 80-88.

439 Wileman, D., Ferro, R.S.T., Fonteyne, R., Millar, R.B. (Eds.), 1996. Manual of Methods of

440 Measuring the Selectivity of Towed Fishing Gears., ICES Coop. Res. Rep., No. 215, 126 pp. 